\title{
Indicators of entrepreneurship activity: some methodological contributions
}

\author{
Instituto de Empresa Business School \\ Serrano 105, 28006 Madrid, Spain \\ E-mail: rachida.justo@ie.edu \\ E-mail: julio.castro@ie.edu \\ *Corresponding author
}

Rachida Justo* and Julio O. De Castro

\author{
Alberto Maydeu-Olivares \\ University of Barcelona \\ and \\ Instituto de Empresa Business School \\ Serrano 105, 28006 Madrid, Spain \\ E-mail: Alberto.maydeu@ie.edu
}

\begin{abstract}
Using a model-based approach, this paper reexamines the measurement of entrepreneurial activity at the national level. Our contribution centres on two main aspects. First, our study allows for the measurement of the likelihood of entrepreneurial behaviour, or entrepreneurial propensity. Second, utilising the social network theory, we introduce the social entrepreneurial environment as a key indicator of the likelihood of entrepreneurial activity.

Using the data provided by the Global Entrepreneurship Monitor (GEM) project, we provide an alternative measure of entrepreneurial activity, which includes entrepreneurial social environment, assumes the existence of a continuum in entrepreneurial behaviour and provides a measure of entrepreneurial propensity. Results indicate that our model provides support for the combined use of entrepreneurial propensity and the entrepreneur's social context.
\end{abstract}

Keywords: entrepreneurship; cross-country; measurement; degrees of entrepreneurship.

Reference to this paper should be made as follows: Justo, R., De Castro, J.O. and Maydeu-Olivares, A. (2008) 'Indicators of entrepreneurship activity: some methodological contributions', Int. J. Entrepreneurship and Small Business, Vol. 6, No. 4, pp.604-621.

Biographical notes: Rachida Justo is a member of the faculty in the Department of Entrepreneurship of the Instituto de Empresa Business School and Assistant to the Associate Dean of Research. She is a doctoral student at the Universidad Autonoma de Madrid. Her research interests include women entrepreneurs and entrepreneurial exit.

Julio O. De Castro is the Associate Dean of Research and Professor of Strategy and Entrepreneurship at the Instituto de Empresa in Madrid, Spain. Professor De Castro's research uses a strategic firm perspective to study piracy, privatisation, transfer of techonology and charateristics of the entrepreneurship 
process. His work has been published in such journals as the Academy of Management Journal, the Journal of Management Studies, and the Journal of International Business Studies, amongst others. He has served on the editorial board of the Academy of Management Journal and serves on the editorial boards of the Journal of Management Studies, The Journal of High Technology Management Research, Journal of World Business, Entepreneurship Theory and Practice, Journal of Small Business Management, Management Research and Revista de Empresa, amongst others. Professor De Castro sits at the board of the Academy of Management and is a founding member and Treasurer of the Iberoamerican Academy of Management.

Alberto Maydeu-Olivares is an Associate Professor of Psychology at the University of Barcelona and Professor of Marketing at the Instituto de Empresa Business School. He obtained a PhD in Quantitative Psychology from the University of Illinois in 1997. His research has focused on quantitative methods in Marketing and in psychology. His areas of expertise are structural equation modelling, item response models, and models for preference data. He has over 40 refereed publications in journals such as the Journal of the American Statistical Association, Psychometrika, or Psychological Methods. Among other distinctions he has received the Cattell Award from the Society of Multivariate Experimental Psychology, the Dissertation Award from the American Psychological Association, and the Young Investigator Award from the Catalan Government.

\section{Introduction}

Measuring the amount and impact of new venture creation and entrepreneurial activity within and across different societies has been an important concern within the entrepreneurship literature (Acs and Storey, 2004; Carree et al., 2002; Reynolds et al., 1999). Many scholars have argued that there is a link between entrepreneurial activity and economic development (OECD, 1998; Verheul et al., 2002), but the measurement of such a link needs to be based on an appropriate criteria.

Scholars are faced with particular difficulties when it comes to cross-country comparisons regarding entrepreneurial activity. Until recently, international entrepreneurship research has fallen short in terms of ensuring sample, instrument and data collection equivalence across-countries (Coviello and Jones, 2004), seriously limiting the validity of research findings. A new and important tool for examining entrepreneurial activity across countries is the Global Entrepreneurship Monitor (GEM) project, which aims at assessing the proportion of the adult population in various countries that are involved in business start-ups at a given point in time. GEM represents a unique attempt to both provide homogeneous cross-country measures of entrepreneurial activity and ascertain the relationship between entrepreneurship and economic development. But even though there is consensus about its importance, entrepreneurship scholars are yet to agree about the appropriateness of the measure used in this project in order to assess and compare entrepreneurial activity within and across countries.

Our contribution centres on two main aspects. First, our study allows for the measurement of the likelihood of entrepreneurial behaviour. Different from prior measures of entrepreneurial activity, where individuals are or not considered entrepreneurs, we argue theoretically and analyse empirically the notion of levels 
and likelihood of entrepreneurial behaviour. Rather than classifying individuals as entrepreneurs or non-entrepreneurs, we adopt a more dynamic view of the phenomenon by letting individuals differ in their propensity to engage in entrepreneurial activities. In doing so, we argue for examining differences over time within countries, as well as across countries.

Second, utilising the social network theory approach, we introduce the social entrepreneurial environment as a key indicator of likelihood of entrepreneurial activity. We contend that the level of an individual's entrepreneurial activity is affected by the social context in which that activity occurs. This context is not uniform and its effects vary because of factors such as social networks, education, gender, etc. As a result, an entrepreneur's personal social network is treated here as a random variable that changes from individual to individual.

The core of our proposed theoretical model lies in the use of two latent continuous variables: the first one reflects an individual's entrepreneurial propensity, that is, his likelihood of engaging in venture creation. The second dimension reflects the individual's social entrepreneurial environment, and captures the elements of a person's adjacent environment that may affect his entrepreneurial propensity. We argue that this measure should be built into the analysis of entrepreneurial activity, and should help provide a strong indicator of the pervasive effects of entrepreneurship.

The purpose of the paper is to propose a new approach to measuring entrepreneurship, one that is complementary to the approaches that have been used recently in cross-country comparisons. Our hypotheses will be tested using data available from the GEM project for comparing entrepreneurship levels across countries. Whilst we recognise the contribution of prior studies measuring entrepreneurial activity (such as the GEM project) as a means of gaining insights into the dynamics of entrepreneurship, we seek to provide a new model of entrepreneurship that, in conjunction with existing measures, will help us reach a more consistent and comprehensive view of the variation of the entrepreneurial phenomena within and across countries.

\section{The measurement of entrepreneurial activity}

While most scholars concur on the need to measure entrepreneurial activity, there is no consensus on how to do it or on the adequacy of previous and current measures (Davidsson, 2004; Dennis, 1997; Dennis, 1999; Gartner and Shane, 1995; Williams, 1993). There are several reasons for this lack of scholarly agreement. First, the extant literature on entrepreneurship has proposed a broad array of different definitions of this phenomenon (Gartner, 1990; Hébert and Link, 1989; Van Praag, 1999; Shane and Venkataraman, 2000). Entrepreneurship is indeed a multidimensional concept, which, depending on the focus of the research and the theoretical perspective adopted, can address very distinct social realities (Bruyat and Julien, 2000; Davidsson, 2004; Verheul et al., 2002).

This diversity of definitions has, in turn, significant implications for the measurement of entrepreneurship levels (Reynolds, 1992a). For instance, final counts can vary depending on the view adopted by researchers to determine who is an entrepreneur; in particular, whether a firm started for the purpose of self-employment is to be included in the measure of entrepreneurship or whether the baseline for inclusion is only value creation and the expectation of future growth. 
Second, the measurement of entrepreneurial activity in a country depends on the level of analysis chosen by the researcher. In their review of longitudinal studies on entrepreneurship, Gartner and Shane (1995) identified two types of research: research focusing on individual level activity (e.g., self-employment) and that mostly concerned with firm-level activity (e.g., organisation creation). However, both approaches present inherent shortcomings; measures focusing on individuals not only ignore firms but might also undercount some specific kinds of entrepreneurs (e.g., self-employed who hire employees). By contrast, firm creation measures often fail to capture businesses started as proprietorships or partnerships.

A third issue raised by researchers deals with the methodological approaches used to measure entrepreneurial activity. Scholars have expressed concerns regarding the undercounting of new firm entries and exits in the market, and the effect of this undercounting on the assessment of the impact of entrepreneurial activity (Bates, 2005; Birley, 1984; Davidsson, 2004; Dennis, 1997; Dennis, 1999; Williams, 1993). Moreover, many of the databases used by entrepreneurship scholars have been designed for purposes other than the study of entrepreneurship, making them a less than suitable tool for gauging the phenomenon from an academic point of view.

Applied to cross-country comparisons, the measurement issues associated with entrepreneurship become even more problematic and the researcher is faced with additional difficulties. On the one hand, the absence of universally agreed upon indicators makes it particularly difficult to provide meaningful and reliable comparisons of the level entrepreneurship across nations (OECD, 1998). Country levels of venture creation can indeed be determined by a wide spectrum of factors, the importance of which varies according to "the disciplinary approach, the level of analysis, the discrimination between demand and supply factors and a distinction between influences on the actual and equilibrium rate of entrepreneurship" (Verheul et al., 2002, p.7).

On the other hand, levels of entrepreneurial activity in a country can be affected by contextual issues such as the existence of a supportive or hostile macro- or microenvironment for venture creation. This argument is consistent with Gartner and Shane's (1995) claim that measures of entrepreneurial rates need to reflect both a longer time frame and some kind of measure of the effect of the environment.

\subsection{Measuring entrepreneurial activity in the GEM project}

The GEM project constitutes an important research tool that can allow entrepreneurship scholars to address the issues related to the measurement of entrepreneurial activity across countries. However, operationalising and implementing the measures used in this project is not ideal and, like any other measure, can be improved. Moreover, the GEM provides a very rich database that has not been fully exploited and we believe that our study can help to present this data in a way that is more respectful of the complex entrepreneurial realities.

One of the better known outcomes of the GEM project is an estimate of a nation's entrepreneurial activity, the Total Entrepreneurship Activity (TEA) index, which is designed to overcome a number of concerns raised in prior research about the measurement of entrepreneurship. Heeding the advice of Gartner and Shane (1995), it is a yearly ongoing measure designed to capture entrepreneurial activity and its effects over time. Trying to meet the challenge of obtaining a representative sample of on going, independent start-up processes and, therefore, addressing the concerns of Dennis (1997), 
Williams (1993) and Birley (1984), the GEM project is also based on a very large random sample of adult individuals. These individuals are presented with three focal screening questions aimed at identifying those in the process of creating a venture:

q1 whether the individual is currently involved in a start-up (indication of being nascent entrepreneur)

q2 whether their current job involves a start-up (nascent intrapreneur)

q3 whether the individual is the owner/manager of a new business (owner/manager).

Individuals who identify themselves as nascent entrepreneurs/nascent intrapreneurs/ or, owners/managers of a new firm, are directed to a longer interview where they are asked specific questions about themselves and their firms. Therefore, the resulting TEA index has the advantage of addressing the issue of levels of analysis raised by Gartner and Shane (1995), because it allows for the capture of individual self-employment as well as new firm creation.

Despite its increasing recognition, the GEM project is still striving to reach full scholarly recognition with respect to its TEA index being a reliable tool for measuring entrepreneurship across countries (Hindle, 2005). We believe that one possible way to diminish researchers' reticence to make the most of the GEM data is by enhancing the measure of entrepreneurship levels for each country. ${ }^{1}$ Therefore, a contribution of this paper is a reexamination of the way entrepreneurial activity is measured using the existing GEM data.

\section{Theoretical background}

In this study we propose an alternative model-based approach to measuring and comparing entrepreneurial activity within and across countries - one that introduces two main modifications to the traditional ones used in measuring the extent of entrepreneurial activity in a country.

Firstly, rather than viewing entrepreneurial activity as an either/or proposition, that is, individuals either are or not entrepreneurs, we introduce the notion of a likelihood for entrepreneurial behaviour. In doing so, our model creates an index that is a continuous variable that allows individuals to vary in their propensity to undertake entrepreneurial activities.

Secondly, and drawing upon thesocial network theory, we base our model on the assumption that entrepreneurial activity is affected by the social context in which that activity occurs, so that a measure of the entrepreneur's personal network, in combination with a measure of its propensity to undertake an entrepreneurial activity, provides a richer measure of the impact and strength of entrepreneurial behaviour in specific countries. Whereas the measurement of direct entrepreneurial activity is important, we believe that it is incomplete without an examination of the entrepreneurial social environment and its impact on the likelihood of venture creation.

\subsection{Measuring a country's entrepreneurial propensity}

Following Gartner's (1989) view that 'who is an entrepreneur?' is the wrong question, we similarly argue that 'how many entrepreneurs there are in a country?' or 'which country has the highest rate of entrepreneurs?' is an incomplete enquiry (Hindle, 2005) 
and should be replaced with an assessment of a country's relative propensity for entrepreneurship. Assuming that entrepreneurs 'are not a well-defined population but a hazy and moving target' (Davidsson, 2004), we believe that researchers should be cautious when comparing the level of nascent entrepreneurial activity across countries and should qualify the TEA index with a measure that captures a country's actual and future entrepreneurial potential.

The TEA national index is computed as the proportion of respondents classified as nascent entrepreneurs in a representative national sample. Each individual in the sample is classified as either an entrepreneur or non-entrepreneur based on his or her responses to the questions $q 1$ to $q 3$ in the GEM survey. We argue that the use of this classification overlooks an essential dimension of the entrepreneurship phenomenon, that is, individuals can show a varying propensity or degree of entrepreneurship.

The concept of 'degrees of entrepreneurship' was first introduced by Cooper and Dunkelberg (1986) to illustrate how the different ways of becoming a business owner exhibited different levels of entrepreneurial intensity. Several scholars took over this notion to explore individual-level (Tay, 1998), as well as organisational-level variations (Schafer, 1990) in entrepreneurial inclination. ${ }^{2}$ More recently, Davidsson (2004) built on this idea and stressed the importance of studying "Why, when and how do individuals, organizations, regions, industries, culture, nations (or other units of analysis) differ in their propensity for the discovery and exploitation of new venture ideas" (Davidsson, 2004, p.29). Following this reasoning, we present an alternative to the TEA measure based on the proposition that entrepreneurial behaviour should be measured on a continuum. Specifically, we claim that rather than treating entrepreneurship as a dichotomous variable, it seems more legitimate to consider that some economic actors show a greater propensity ${ }^{3}$ for entrepreneurship than others.

\section{H1a Individuals' propensity for entrepreneurial activity is a latent continuous variable} with multiple possible indicators.

\section{HIb Particular instances of entrepreneurial activity (such as being involved in a start-up) are linked to individuals' propensity for entrepreneurial activity via a threshold relationship.}

\subsection{The role of the entrepreneur's social network}

Research in sociology suggests that positions in a social structure influence the attitudes, behaviours and outcomes of the actors occupying those positions (Granovetter, 1985). In the field of entrepreneurship, social influence is studied by looking at interorganisational networks and the entrepreneur's personal network. Our study draws on this second theoretical construct and studies its impact on the incidence of venture creation. We adopt Gilmore and Carson's (1999, p.31) definition of a network as: "A collection of individuals who may or may not be known to each other and who, in some way contribute something to the entrepreneur, either passively, reactively or proactively whether specifically elicited or not." The most prevalent tenet in personal network-based entrepreneurship studies is that persons involved in pro-entrepreneurship networks are more likely to engage in entrepreneurship (Aldrich and Zimmer, 1986). If we think of ideas, knowledge and capital as the main components entrepreneurs must 
assemble in firm creation, social relations provide the connections required to unite these ingredients. Social relations shape information flows allowing for the identification of promising opportunities, and trace the ties through which capital flows, helping entrepreneurs to overcome obstacles to resource mobilisation.

Although there have been few attempts to link micro social structures empirically to the incidence of entrepreneurial activity, sociology scholars repeatedly insist that personal links have a direct impact on an individual's decision to launch a new venture (Stuart and Sorenson, 2004). Some have also argued that traditional approaches to research on international entrepreneurship have neglected the relational nature of the entrepreneurial process, overemphasising deterministic models based on national culture (Aldrich and Zimmer, 1986).

The personal social network construct is particularly useful in studying countries' entrepreneurial propensity as an aggregate of the individuals' odds of engaging in entrepreneurship. We believe that this approach provides several advantages over others in explaining the creation of new firms. These advantages include:

- the integration of the environmental context

- its dynamic perspective

- its ability to explain why some individuals start firms while others do not (Aldrich and Zimmer, 1986; Johannisson, 1987; O’Donnell et al., 2001).

Based on GEM data, our study introduces three types of variables that reflect the extent of an individual's inclusion in an entrepreneurial social network:

Knowing an entrepreneur is one of the most obvious drivers of an individual's familiarity with and inclination towards an entrepreneurial career. As stated above, entrepreneurs need to establish connections in order to identify an opportunities and assemble the resources needed to begin operations. At some point before or during this process, entrepreneurs might be influenced by relations with socialising agents who motivate and help them to start their ventures.

Business angel activity is not only a direct manifestation of entrepreneurial endeavours; it is also proof of a person's privileged position in an entrepreneurial network. As Stuart and Sorenson (2004) stated:
"One reason why social networks shape the entrepreneurial process so importantly is that they provide the conduits through which private information flows. To the extent that individuals occupy heterogeneous positions in networks, they vary in their access to this information. And to the degree that the recognition of entrepreneurial opportunities hinges on access to private information, differences in network positions can thus explain much of the inter-individual variance in access to the knowledge required to discern attractive opportunities for new ventures." (p.213)

In this sense, when individuals contribute to entrepreneurial activity as investors, they become part of the entrepreneurial network involved in the venture creation process. Their integration in this particular circle process provides them with continuous feedback and information that is likely to stimulate even more interest in, and knowledge about, the entrepreneurial process. 
The perception of good opportunities in one's region: ${ }^{4}$ The geography of entrepreneurial activity is considered by several scholars as a significant implication flowing from the influence of social network structure on opportunity identification and resource mobilisation, giving birth to the popular 'industrial district thesis'. This perspective can be typified by the idea that:

"Because entrepreneurs utilize the contacts in their social networks to found firms, because individuals' contact networks concentrate in the region in which they work and live, and because established firms produce many of the resources consumed in new venture creation (tacit knowledge and skilled labour), new firms in an industry tend to arise in the same locations as existing ones." (Stuart and Sorenson, 2004, p.221)

Our research builds on this idea and connects it with the above-mentioned argument that a person's likelihood of engaging in entrepreneurship depends on his privileged position within an entrepreneurial network. Indeed, there are reasonable arguments to assume that the identification of a good opportunity in one's region reflects, to some extent, the opportunities and constraints that arise from the relations that embed a focal individual in a social circle. The more individuals are embedded in social circles that are favourably disposed towards entrepreneurship, the more good opportunities they will see.

\subsection{The relationship between entrepreneurial propensity and social networks}

The evidence and arguments from previous research point to the fact that research concentrating only on measuring firm entries understates the extent of entrepreneurial activity and its impact on society. Krueger and Brazeal (1994) argue that:

"Few research studies have conceptualized or measured entrepreneurial potential, though interest in pre-emergence entrepreneurial activity has recently grown [...]. However, measures of entrepreneurial potential seem to remain wedded to various ad hoc profiles of personality and demographic characteristics with minimal predictive validity." (p.92)

Recognising that entrepreneurial activity does not occur in a vacuum, the authors discussed the importance of developing an 'entrepreneurial potential' so that potential entrepreneurs can find suitable conditions to develop their ideas.

Some traditional approaches to entrepreneurship have posited the existence of differing 'propensities to entrepreneurship' according to national or cultural origins. Although it is widely recognised that culture and social norms have an indirect effect on entrepreneurial career choices (Davidson, 1995; Verheul et al., 2001; Wennekers et al., 2001), there is a feeling among some researchers that these sociocultural models of entrepreneurship are overly deterministic (Aldrich and Zimmer, 1986).

In this study we build on previous literature and argue the existence of environmental influence that affects an individual's entrepreneurial propensity. But rather than drawing on overdeterministic models, we turn our attention to the situational conditions under which entrepreneurs undertake venture creation. Specifically, we contend that the social entrepreneurial environment affects the level of entrepreneurial activity and the addition of a model of social network to entrepreneurial activity provides a robust description of the entrepreneurship process. Thus: 
H2 Entrepreneurial activity will be positively affected by the social entrepreneurial environment.

\subsubsection{Methods and analysis}

For this study we used a sample of 7000 Spanish respondents to the 2003 GEM survey. The sample was obtained through interviews by a survey firm specialised in phone surveys.

While the current TEA index is built around direct measures of an individual's entrepreneurial activity (independent start-up, current job involves start-up, current owner/manager of business), it does not include other indirect or environmental indicators of activity that also have a real impact on an individual's entrepreneurial activity. Nevertheless, GEM's datasets do provide several types of environmental indicators: macro-level measures of a country's environment for entrepreneurship, expert's assessment of their country's entrepreneurial environment and adult individuals' assessment of their perceived proximate environment.

This third set of variables is of special interest for this paper since it offers the possibility of using responses from a sample of entrepreneurs and non-entrepreneurs; two groups that show significant differences in their perceptions of the entrepreneurial environment. Moreover, consistent with Dennis (1997) and Aldrich and Waldinger (1990), within the analysis of the environment we concentrate on the examination of environment familiarity and intrapopulation processes, since these variables relate to the proximate entrepreneurial environment of individuals, that is, the elements of the environment that are close to a person, and that may foster her/his propensity to launch a business. This proximate environment is, in our opinion, more likely to influence an individual's behaviour.

Our model is based on the assumption that an individual's entrepreneurial activity and proximate environment are latent continuous variables that are related to the observed survey questions through a threshold relationship. We provide an assessment of the goodness of fit of our proposed model, and we propose linear combinations of the GEM indicators that can be used as valid proxies of the latent variables in our model.

Consistent with GEM's specification of TEA, we used three indicators of direct entrepreneurial activity ( $q 1, q 2$ and $q 3)$ and included three indicators from the GEM survey of the social entrepreneurial environment:

q4 business angel activity

q5 know an entrepreneur

q6 good start-up opportunities in your area.

An important assumption of this research is that the variables $q 1-q 3$ and $q 4-q 6$ are proxies for two unobservable (continuous) constructs, entrepreneurial activity, and social entrepreneurial environment, respectively. Table 1 provides the frequencies for the GEM variables used in this study. Five individuals refused to respond to one or more of these variables and were deleted from further analysis. Thus, the effective sample size is 6995 observations. 
Table 1 Frequencies of selected variables

\begin{tabular}{llcccc}
\hline Code & Variable & No & Don't know & Yes & Total \\
\hline q1 & Independent start-up? & 6708 & 0 & 297 & 7005 \\
q2 & Current job involves a start-up? & 6877 & 4 & 114 & 6995 \\
q3 & Owner/manager of a business? & 6333 & 1 & 661 & 6995 \\
q4 & Business angel in past three years? & 6766 & 0 & 229 & 6995 \\
q5 & Know entrepreneur in last two years? & 4769 & 144 & 2082 & 6995 \\
q6 & Start-up opportunities within next six months? & 3097 & 1580 & 2318 & 6995 \\
\hline
\end{tabular}

We hypothesise that a two-factor model underlies an individual's response to our survey questions as depicted in Figure 1. The first latent variable (factor) corresponds to the individual's propensity to engage in entrepreneurial activity (EP). This factor has four indicators ( $q 1$ to $q 4$ ). The second latent variable corresponds to the individual's Social Entrepreneurial Environment (SEE) with three indicators $(q 4, q 5, q 6)$. We also hypothesise that individuals' entrepreneurial propensities are determined by their social entrepreneurial environment, which is unique for each individual (that is, it changes from individual to individual).

Figure 1 A two dimensional model of entrepreneurship

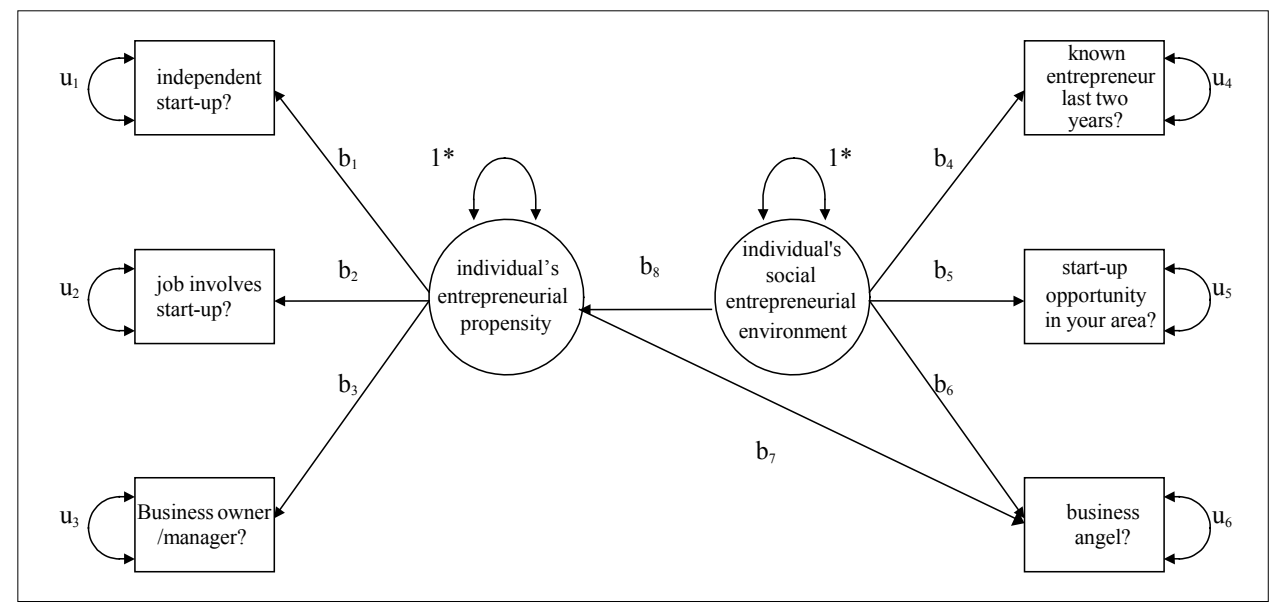

Note: $\quad *$ Parameter fixed for identification purposes.

Consistent with this view, we present a model of entrepreneurial propensity and social entrepreneurial environment and argue that there is a relationship between these two dimensions - both determined on the basis of a number of proxy variables. Figure 1 presents our model.

Since the model's random errors and latent variables are likely to be induced by a large set of specific causes, we assume that the random errors and latent variables are normally distributed. Now, to link this theoretical model to the observed individual responses, we assume a threshold relationship such that for each observed variable: 


$$
q_{i}=\left\{\begin{array}{ccc}
\text { No } & \text { if } & q_{i}^{*}<\tau_{i, 1} \\
\text { Don't know } & \text { if } & \tau_{i, 1} \leq q_{i}^{*} \leq \tau_{i, 2} \\
\text { Yes } & \text { if } & q_{i}^{*}>\tau_{i, 2}
\end{array}\right.
$$

where the $\tau$ 's are thresholds that change from variable to variable, and the $q_{1 i}^{*}$ 's are propensity scores assumed to underlie each of the observed categorical responses.

Note that we assume that 'don't know' responses provide information about the individuals' entrepreneurial propensities and social environment. ${ }^{5}$ Furthermore, the incorporation of 'don't know' responses into the model leads to a substantial reduction in missing patterns. Had we discarded 'don't know' responses, the effective sample size would be 5313 (a $24 \%$ data loss).

We fitted this structural equation model using Mplus (Muthén and Muthén, 2001). The model fits well given the large sample size employed: $\chi^{2}=15.1$ on $7 \mathrm{df}(\mathrm{p}=0.03)$, RMSEA $=0.01$. Table 2 provides the slope parameter estimates for the model in Figure 1 along with their standard errors. Also, Table 3 provides the $\mathrm{R}^{2}$ for each of the six variables used.

Table 2 Parameter estimates and standard errors for the slope parameters

\begin{tabular}{lcccccccc}
\hline Parameter & $b 1$ & $b 2$ & $b 3$ & $b 4$ & $b 5$ & $b 6$ & $b 7$ & $b 8$ \\
\hline Value & 0.51 & 0.86 & 0.45 & 0.65 & 0.24 & 0.30 & 0.18 & 0.47 \\
SE & 0.04 & 0.06 & 0.04 & 0.08 & 0.03 & 0.08 & 0.07 & 0.09 \\
\hline
\end{tabular}

Note: $\quad \mathrm{N}=6995$.

Table 3 Proportion of variance accounted for

\begin{tabular}{llc}
\hline Code & Variable & $R^{2}$ \\
\hline q1 & Independent start-up? & 0.32 \\
q2 & Current job involves a start-up? & 0.90 \\
q3 & Owner/manager of a business? & 0.25 \\
q4 & Business angel in past three years? & 0.18 \\
q5 & Know entrepreneur in last two years? & 0.42 \\
q6 & Start-up opportunities within next six months? & 0.06 \\
\hline
\end{tabular}

As can be seen from these tables, the variable worst accounted for by the model is whether there will be good start-up opportunities within the next six months $\left(\mathrm{R}^{2}=6 \%\right)$. On the other hand, the variable best accounted for by the model is whether the current job involves a start-up $\left(\mathrm{R}^{2}=90 \%\right)$. The latter is the best indicator of the individuals' propensity to engage in entrepreneurial activities (see Table 2). On the other hand, the best indicator of the individuals' business environment is whether they have known an entrepreneur in the last two years. Finally, as we had hypothesised, being a business angel is a weak (although significant) proxy of an individual's propensity to be involved in entrepreneurial activities. 
Of particular interest is the effect of an individual's propensity to engage in entrepreneurial activities on his/her social entrepreneurship environment. This effect is significant and strong, $\mathrm{R}^{2}=18 \%$.

In closing, we have verified that our model for GEM's measure of entrepreneurship is supported by the data. This model assumes two continuous latent variables as opposed to the TEA's current binary classification of respondents as either entrepreneurs or non-entrepreneurs. Our model enables researchers to draw powerful statistical inferences regarding the entrepreneurship phenomenon. In our model, the main quantities of interest are the means for the latent variables concerning an individual's propensity to engage in entrepreneurial activities and an individual's entrepreneurial environment. Interest lies in investigating how these means change over time within a country and across countries. Furthermore, the model allows for the comparison of thresholds and latent variable slopes over time within a country, and for comparisons across different countries. Finally, and most interestingly, by incorporating additional exogenous variables into our model, such as an individual's background, country economic variables, and a country's cultural environment, it is possible to investigate the effects of these background variables on the model's latent means, thresholds, and latent variable slopes, in a manner similar to multivariate probit analysis (see Muthén, 1979; Browne and Arminger, 1995; Tay, 1998). However, although statistically optimal, the approach advocated here requires considerable statistical expertise. Therefore, in the next section we consider constructing linear combinations of the indicators that can be used as an approximation of our model's latent variables.

\subsection{Proxies for the latent variables}

Point estimates and standard errors for each individual's standing on the two latent variables in our model of the level of entrepreneurship can be obtained by integrating the posterior distribution of the latent variables, given their responses to the six indicators considered in this study. We investigate in this section whether suitable proxies for these estimates can be alternatively obtained by the following procedure. We code the responses to the indicators q1 to q6 as 'No' $=0$, 'Don't know' $=1$, and 'Yes $=2$ '. Then we compute:

$$
\begin{aligned}
& E P=(q 1+q 2+q 3+q 4) / 8 \\
& S E E=(q 4+q 5+q 6) / 6 .
\end{aligned}
$$

Here, EP and SEE are normalised indices (that is, they range between 0 and 1) of an individual's propensity to engage in entrepreneurial activities and of an individual's entrepreneurial environment, respectively. To investigate the convergent and discriminant validity of these proxies, we calculated the correlations between these proxies and the point estimates of the latent variables. These are shown in Table 4.

As can be seen in the table, our proposed proxies correlate .90 with the point estimates of our model's latent variables. Hence, they show high convergent validity and can be used as valid proxies for the latent variables. However, note that the use of proxies underestimates the correlation between entrepreneurial activity and entrepreneurial environment because it does not take into account the unreliability of the proxies. The correlation between the proxies is only 0.22 (see Table 4) whereas the correlation between the latent variables is 0.47 (see b8 in Table 2). 
Table 4 Correlations among the TEA, point estimates of the latent variables, and latent variables proxies

\begin{tabular}{lccc}
\hline & $T E A$ & $E P$ & SEE \\
\hline Entrepreneurial Activity & .73 & .89 & .47 \\
Social Entrepreneurial Environment & .29 & .41 & .90 \\
TEA & 1 & .70 & .10 \\
EP & .70 & 1 & .22 \\
SEE & .10 & .22 & 1 \\
\hline
\end{tabular}

Notes: All correlations are significant $(\alpha=.01)$; entrepreneurship activity and environment are the point estimates of the latent variables; EP and SEE are our proxies of those latent variables.

Most interestingly, the TEA index correlates 0.70 with the proxy of entrepreneurial activity but only 0.10 with the proxy of social entrepreneurial environment. Thus, although based on rather different principles, our measure of economic activity correlates quite highly with the TEA index.

\subsubsection{Discussion}

The measurement of entrepreneurial activity in different countries is an important concern both for researchers interested in entrepreneurship and for public policy concerns (Birley, 1984; Dennis, 1997; Haswell and Holmes, 1989; Laitinen, 1992; Williams, 1993). In this paper we have reexamined the approach to measuring entrepreneurial activity, introducing the notion of likelihood of entrepreneurial activity. This implies a change in the way entrepreneurship is viewed from one in which a person is or not an entrepreneur to the notion of levels of entrepreneurship in individuals. Moreover, we include and measure the effects of entrepreneurial environment on entrepreneurial activity. We believe these are significant contributions to the examination and measurement of entrepreneurial activity.

One important addition in our measure is that it provides a model-based approach to measuring entrepreneurial activity; one that incorporates an individual's social entrepreneurial environment in the measure. Network-based arguments clearly have significant potential to enhance our understanding of an individual's propensity to engage in entrepreneurship. In this sense, our study addresses the concerns of sociology scholars by providing an empirical tests and validation of the general assertion that the incidence of entrepreneurial activity hinges on the structure of an individual's social network. Consistent with these theoretical arguments, our results indicate that an individual's personal context significantly affects his odds of undertaking direct entrepreneurial activity, and suggest that failing to consider such effect significantly understates the extent of entrepreneurship in a country.

The metrics in this study are also an improvement over previous approaches because they are transparent and result in a propensity score for entrepreneurial activity that is normalised and continuous. This point is a significant departure from prior research in entrepreneurship, and in particular from the GEM's TEA measure. The use of a classification, as in the TEA, in which individuals are determined to be either entrepreneurs or not entrepreneurs reflects a static approach at the phenomena, whereas 
the use of propensity, calculated as a variable ranging from 0 to 1 , allows researchers to take a dynamic view of the process and to incorporate the notion of the likelihood of entrepreneurship over time. This, we believe, is a significant contribution, and one that merits rethinking the traditional approaches to examining entrepreneurial activity.

Important also is the introduction of the notion of thresholds in the context of new venture creation. On top of the examination of entrepreneurial activity (in terms of propensity), our model also allows us to examine the thresholds that determine when people start firms. This is a very important point for both research and public policy. From the perspective of research it gets us closer to determining the points that determine the likelihood of new venture creation. Our future examinations in this area will focus in better determining the characteristics of those thresholds.

The research also allows for an analysis of the percentage of the variance accounted for by each element in the model. Our model has a $90 \%$ prediction rate for entrepreneurial activity based on whether the current job of the person involves a start-up, and a $32 \%, 25 \%$ and, $18 \%$ prediction rate based on whether it involves an independent start-up, an owner/manager of a business or being a business angel, respectively. Consistent with previous evidence, the strongest predictor of entrepreneurial activity is whether the current job of the individual involves a start-up.

As long as we adhere to a dynamic perspective of the entrepreneurship phenomenon and view individuals as having a certain propensity to be entrepreneurs, then we can more effectively make inferences about a country's comparative strength in entrepreneurship. This approach may not completely resolve the question of how to ideally compare one country's entrepreneurial activity with another, but it takes a step closer to measuring this difference in a more consistent manner. Moreover, we believe that this approach challenges us to develop research questions, methodologies and techniques that will do justice to the complexity of entrepreneurship (Gartner, 1985; Gartner, 1989). Indeed, we argue that entrepreneurial activity is not a clear-cut reality that can be roughly put down in numbers; rather, entrepreneurship is a potential that people have in certain degrees and that, combined with specific circumstances, can give birth to actual venture creation.

One caveat is important to discuss at this point. It is important to realise that both the TEA and our measures of EP and SEE are simply indices. They do not represent the percentage of actual and potential entrepreneurs. While it is tempting to think about the TEA as percentage of entrepreneurs, and there is evidence that it is sometimes misused as such, the value of these indices lies in the ability to compare across time, and countries and regions rather than provide absolute values of entrepreneurial activity.

Finally, we recognise that the measurement of entrepreneurial activity will always be a contentious matter and it is not our intention to reopen up the debate on a definition of entrepreneurship. Nevertheless, we consider that proposing an alternative and consistent measure for international comparison of entrepreneurship could significantly contribute to the advancement of academic knowledge as well as provide policymakers with useful inputs for designing programmes to enhance the economic welfare of their countries in the context of global competition. 


\section{Acknowledgements}

Support for this research comes from a grant from Fundación BBVA, Madrid, Spain. Rachida Justo and Julio de Castro are grateful for support by the Spanish Ministerio de Educación y Ciencia through project SEJ2006-10915/ECON.

\section{References}

Acs, Z.J., Arenius, P., Hay, M. and Minniti, M. (2005) Global Entrepreneurship Monitor 2004 Executive Report, London: Babson College and London Business School.

Acs, Z.J. and Storey, D. (2004) 'Introduction: entrepreneurship and economic development', Regional Studies, Vol. 38, No. 8, pp.871-877.

Aldrich, H. and Zimmer, C. (1986) 'Entrepreneurship through social networks', in D.L. Sexton and R.W. Smilor (Eds.) The Art and Science of Entrepreneurship, Cambridge, MA: The Ballinger Publishing Company, pp.3-23.

Aldrich, H.E. and Waldinger, R. (1990) 'Ethnicity and entrepreneurship', Annual Review of Sociology, Vol. 16, pp.111-135.

Bates, T. (2005) 'Analysis of young, small firms that have closed: delineating successful from unsuccessful closures', Journal of Business Venturing, Vol. 20, No. 3, pp.343-358.

Birley, S. (1984) 'Finding the new firm', Proceedings of the Academy of Management, Vol. 47, pp.64-68.

Browne, M.W. and Arminger, G. (1995) 'Specification and estimation of mean and covariance structure models', in G. Arminger, C.C. Clogg and M.E. Sobel (Eds.) Handbook of Statistical Modeling for the Social and Behavioral Sciences, New York: Plenum Press, pp.185-249.

Bruyat, C. and Julien, P-A. (2000) 'Defining the field of research in entrepreneurship', Journal of Business Venturing, Vol. 16, pp.165-180.

Carree, M.A., van Stel, A., Thurik, A.R. and Wennekers, A.R.M. (2002) 'Economic development and business ownership: an analysis using data of 23 modern economies in the period 1976-1996', Small Business Economics, Vol. 19, No. 3, pp.271-291.

Cooper, A. and Dunkelberg, W.C. (1986) 'Entrepreneurship and paths to business ownership', Strategic Management Journal, Vol. 7, No. 1, pp.53-69.

Coviello, N.E. and Jones, M.V. (2004) 'Methodological issues in international entrepreneurship research', Journal of Business Venturing, Vol. 19, No. 4, pp.485-508.

Davidson, P. (1995) 'Culture, structure and regional levels of entrepreneurship', Entrepreneurship and Regional Development, Vol. 7, pp.41-62.

Davidsson, P. (2004) Researching Entrepreneurship, New York: Springer Verlag.

Dennis, W.J., Jr. (1997) 'More than you think: an inclusive estimate of business entries', Journal of Business Venturing, Vol. 12, May, pp.175-196.

Dennis, W.J., Jr. (1999) 'Business starts and stops', Wells Fargo/NFIB Series, Washington, DC: The NFIB Education Foundation, November.

Gartner, W.B. (1985) 'A conceptual framework for describing and classifying the phenomenon of new venture creation', Academy of Management Review, Vol. 10, No. 4, pp.696-706.

Gartner, W.B. (1989) 'Who is an entrepreneur is the wrong question', Entrepreneurship Theory and Practice, pp.47-68.

Gartner, W.B. (1990) 'What are we talking when we talk about entrepreneurship?', Journal of Business Venturing, Vol. 5, No. 1, pp.15-28.

Gartner, W.B. and Shane, S.A. (1995) 'Measuring entrepreneurship over time', Journal of Business Venturing, Vol. 10, No. 4, pp.283-301. 
Gilmore, A. and Carson, D. (1999) 'Entrepreneurial marketing by networking', New England Journal of Entrepreneurship, Vol. 12, No. 4, pp.31-38.

Granovetter, M. (1985) 'Economic action and social structure: the problem of embeddedness', American Journal of Sociology, Vol. 91, No. 3, pp.481-510.

Haswell, S. and Holmes, S. (1989) 'Estimating the small business failure rate: a reappraisal', Journal of Small Business Management, July, pp.68-74.

Hébert, R.F. and Link, A.N. (1989) 'In search of the meaning of entrepreneurship', Small Business Economics, Vol. 1, No. 1, pp.39-49.

Hindle, K. (2005) A Measurement Framework for International Entrepreneurship Policy Research: From Impossible Index to Malleable Matrix, Unpublished document.

Johannisson, B. (1987) 'Anarchists and organizers-entrepreneurs in a network perspective', International Studies of Management and Organization, Vol. 17, pp.49-63.

Kollmann, T., Christofor, J. and Kuckertz, A. (2005) 'Explaining entrepreneurial orientation: conceptualization of a cross-cultural research framework', Paper Presented at the EURAM 2005 Conference, Munich, 4-7 May.

Krueger, N.F., Jr. and Brazeal, D.V. (1994) 'Entrepreneurial potential and potential entrepreneurs', Entrepreneurship Theory and Practice, Vol. 18, No. 3, pp.91-104.

Laitinen, E.K. (1992) 'Prediction of failure of a newly founded firm', Journal of Business Venturing, Vol. 7, No. 4, pp.323-340.

Muthén, B. (1979) 'A structural probit model with latent variables', Journal of the American Statistical Association, Vol. 74, pp.807-811.

Muthén, L. and Muthén, B. (2001) MPLUS, Los Angeles, CA: Muthén \& Muthén.

O'Donnell, A., Gilmore, A., Cummins, D. and Carons, D. (2001) 'The network construct in entrepreneurship research: a review and critique', Management Decision, Vol. 39, No. 9, pp.749-760.

OECD (1998) Fostering Entrepreneurship, the OECD Jobs Strategy, OECD, Paris.

Parnell, J.A., Crandall, W.R. and Meneffee, M. (1995) 'Examining the impact of culture on entrepreneurial propensity', Academy of Entrepreneurship Journal, Fall, Vol. 1, No. 1, pp.39-52.

Reynolds, P.D. (1992a) 'Predicting new-firm births: interactions of organizational and human populations', in D.L. Sexton and J.D. Kasarda (Eds.) The State of the Art of Entrepreneurship, Boston: PWS-Kent, pp.268-300.

Reynolds, P.D., Bygrave, W.D., Autio, E., et al. (2004) GEM GLOBAL REPORT 2003, Boston: Babson, London Business School and Kaufmann Foundation.

Reynolds, P.D., Hay, M. and Camp, S.M. (1999) Global Entrepreneurship Monitor. 1999 Executive Report, London: Babson College, London Business School and the Kauffman Center for Entrepreneurial Leadership.

Robinson, P.B., Stimpson, D.J. and Hunt, H. (1991) 'An attitude approach to the prediction of entrepreneurship', Entrepreneurship Theory \& Practice, Vol. 15, No. 4, pp.13-31.

Schafer, D.S. (1990) 'Level of entrepreneurship and scanning source usage in very small businesses', Entrepreneurship Theory and Practice, Vol. 15, No. 2, pp.19-31.

Shane, S. and Venkataraman, S. (2000) 'The promise of entrepreneurship as a field of research', Academy of Management Review, Vol. 25, No. 1, pp.217-227.

Stuart, T.E. and Sorenson, O. (2004) 'Social networks and entrepreneurship', in R. Agarwal, S. Alvarez and O. Sorenson (Eds.) Handbook of Entrepreneurship, Kluwer, pp.211-228.

Tay, R.S. (1998) 'Degree of entrepreneurship: an econometric analysis using the ordinal probit model', Journal of Small Business and Entrepreneurship, Vol. 15, No. 1, pp.83-99.

Van Praag, M.C. (1999) 'Some classic views on entrepreneurship', The Economist, Vol. 147, No. 3, pp.311-335. 
Verheul, I., Wennekers, S., Audretsch, D. and Thurik, R. (2001) 'An eclectic theory of entrepreneurship', Tinbergen Institute Discussion Paper, TI 2001-030/3.

Verheul, I., Wennekers, S., Audretsh, D. and Thurik, R. (2002) 'An eclectic theory of entrepreneurship: policies, institutions and culture', in D. Audretsch, R. Thurik, I. Verheul and S. Wennekers (Eds.) Entrepreneurship: Determinants and Policy in a European-US Comparison, Boston: Kluwer Academic Publishers, pp.11-82.

Wennekers, A.R.M., Noorderhaven, N.G., Hofstede, G. and Thurik, A.R. (2001) 'Cultural and economic determinants of business ownership across countries', Proceedings, Babson Conference, Jönköping, 13-16 June.

Williams, M.L. (1993) 'Measuring business starts, success and survival: some database considerations', Journal of Business Venturing, Vol. 8, pp.295-299.

\section{Bibliography}

Acs, Z.J., Carlsson, B. and Karlsson, C. (1999) Entrepreneurship, Small and Medium-sized Enterprises and the Macroeconomy, Cambridge: Cambridge University Press.

Aldrich, H.E. (1990) 'Using an ecological perspective to study organizational founding rates', Entrepreneurship Theory and Practice, Vol. 14, No. 3, pp.7-24.

Aldrich, H.E., Elam, A. and Reese, P.R. (1996) 'Strong ties, weak ties and strangers: do women business owners differ from men in their use of networking to obtain assistance?', in S. Birley and I. MacMillan (Eds.) Entrepreneurship in a Global Context, London: Routledge.

Aldrich, H.E., Kalleberg, A., Marsden, P. and Cassell, J. (1989) 'In pursuit of evidence: sampling procedures for locating new businesses', Journal of Business Venturing, Vol. 4, pp.367-386.

Audretsch, D.B. and Thurik, A.R. (2000) 'Capitalism and democracy in the 21st century: from the managed to the entrepreneurial economy', Journal of Evolutionary Economics, Vol. 10, No. 1, pp.17-34.

Blanchflower, D.G. (2000) 'Self-employment in OECD countries', Labour Economics, Vol. 7, pp.471-505.

Chandler, G.N. and Lyon, D. (2001) 'Issues of research design and construct measurement in entrepreneurship research: the past decade', Entrepreneurship Theory and Practice, Summer, Vol. 25, No. 4, pp.101-113.

De Castro, J., Pistrui, J., Coduras, A., Cohen, B. and Justo, R. (2001) The Global Entrepreneurship Monitor (GEM). Executive Report Spain 2001, Najeti Chair-Instituto de Empresa, Madrid.

Dodd, S.D. (1997) 'Social network membership and activity rates: some comparative data', International Small Business Journal, Vol. 15, No. 4, pp.80-87.

Gnyawali, D.R. and Fogel, D.S. (1994) 'Environment for entrepreneurship development: key dimensions and research implications', Entrepreneurship Theory and Practice, Vol. 18, pp.43-62.

Kirchhoff, B.A. and Phillips, B.D. (1989) 'The effect of firm formation and growth on job creation in the United States', Journal of Business Venturing, Vol. 3, pp.261-272.

Krueger, N.F. (1993) 'The impact of prior entrepreneurial experience on perceived new venture feasibility and desirability', Entrepreneurship Theory \& Practice, Vol. 18, No. 1, pp.5-21.

Reynolds, P.D. (1992b) 'Sociology and entrepreneurship. Concepts and contributions', Entrepreneurship Theory and Practice, Vol. 16, No. 2, pp.47-70.

Reynolds, P.D., Storey, D.J. and Westhead, P. (1994) 'Cross-national comparisons of the variation in new firm formation rates', Regional Studies, Vol. 28, No. 4, pp.443-456.

Sternberg, R. and Litzenberger, T. (2004) 'Regional clusters in Germany - their geography and their relevance for entrepreneurial activities', European Planning Studies, Vol. 12, No. 6, p.767. 
Storey, D.J. (1999) 'Six steps to heaven: evaluating the impact of public policies to support small business in developed economies', in D.L. Sexton and H. Landström (Eds.) Handbook of Entrepreneurship, Blackwell: Oxford, pp.176-194.

Ucbasaran, D., Westhead, P. and Wright, M. (2001) 'The focus of entrepreneurial research: contextual and process issues', Entrepreneurship Theory and Practice, Summer, Vol. 25, No. 4, pp.57-80.

Wennekers, A.R.M. and Thurik, A.R. (1999) 'Linking entrepreneurship and economic growth', Small Business Economics, Vol. 13, No. 1, pp.27-55.

\section{Notes}

1 While we acknowledge that the GEM project would benefit from a substantial rework of the questionnaire currently used, changes in the questionnaire affect the ability for continuous and longitudinal analysis. The improvements proposed in this paper relate to the approach taken in measuring entrepreneurial activity, not to the questionnaire itself.

2 It is important to note that the notion of propensity to entrepreneurship used in this paper is different from a similar concept used by some scholars, which adopts a trait's approach to defining entrepreneurs and the odds of a person to become an entrepreneur. This is the case, for example, of the 'entrepreneurial attitude orientation' construct, which is positioned in the field of sociology (Robinson et al., 1991) used to measures the entrepreneurial attitude along three dimensions: behaviour, belief and emotion. It is, however, interesting to note that Kollmann et al. (2005) consider all these three factors to be connected to the individual's attitude towards a particular environmental stimulus. Our study establishes the same kind of connection.

3 Although we acknowledge that the idea of entrepreneurial propensity should not be limited to quantitative differences, in this article we will concentrate on this dimension since the GEM explores the qualitative dimension quite effectively. The project uses the distinction between 'opportunity-based' and 'necessity-based' entrepreneurship to illustrate how nations may have similar start-up rates that represent very different levels of real and profitable entrepreneurial opportunities" (see Acs et al., 2005; Davidsson, 2004; Reynolds et al., 2004).

4 It should be noted here that the perceived opportunity is also used in some models as a measure of an individual's propensity to entrepreneurship (for example, Parnell et al., 1995). However, these models focus on the individuals' perceptions to explain behaviour, while our approach stresses the inclusion of the external environment condition, in particular the one immediately related to the individual, as a trigger for entrepreneurial behaviour.

5 Our model is based on the assumption that data in GEM is not missing randomly. Davidsson (2004) expressed concerns about the problem of the GEM relying on "the respondent's subjective interpretation of what should and should not be counted as "now trying to start a business". He also claimed that the problem could vary according to cultural differences, noting the example of Germany and Ireland, where a considerable proportion of 'no' and 'don't know' answers might occur when the respondent would have liked to say 'yes'. Following the idea of 'degrees of entrepreneurship' stated before, we assume that the pattern observed by the missing data is the following: when the respondent answers 'don't know', he is in fact choosing an intermediate answer between the 'yes' and the 'no'. 